\title{
Bangladesh's Flooding: Coping Strategies of Flood Affected People of Nageshwari Upazila
}

\author{
Mehraz Hossain Sarker \\ Project Coordinator (Bangladesh) \\ Deutsche Welle (DW) \\ Kurt-Schumacher Straße 3 \\ 53 II 3 Bonn, Germany \\ E-mail: mehraz-hossain.sarker@dw.com \\ K. M. Sujauddin \\ Assistant Professor \\ Department of Sociology \\ Jagannath University, Dhaka, Bangladesh \\ E-mail: sujasocjnu@gmail.com
}

Received: August 06, 2020

Accepted: August 18, 2020

Online Published: September 06, 2020

doi: 10.46281 /aijsst.v5i3.749

URL: https://doi.org/I0.4628I/aijssr.v5i3.749

\begin{abstract}
Flood is one of the most common natural disasters in Southeast Asia, especially in Bangladesh. Extreme flood inundates more than half of the developing country's landmass causing immense suffering to human life, damages properties, and economy. Furthermore, flood protection and management have been emphasized in terms of the sustainable development approach against climate impacts. As a result, Bangladesh has developed distinct indigenous practices to protect themselves from floods. The study aimed to identify the coping mechanisms and indigenous knowledge and the barriers to using these mechanisms. The study was conducted in two unions named Ratanpur and Nunkhawa of Nageshwari Upazila which is an Upazila of Kurigram District of Bangladesh. A mixed-method was used for the study. The survey questionnaire, focus group discussion (FGD) and key informants' interviews (KII) were used as the tools for collecting data. Most of the respondents were farmers who had very minimal income level. Even though respondents used the shelter center during the flood incident, selling assents, letting children work, multiple works, extra labor were the fundamental strategies to overcome financial damage. The most common challenges faced by the victims to overcome the situation were the financial scarcity and recovering wasted crops. Filing to recover the vulnerability made some of the respondents migrate to another city or place. Proper money lending and credit system at reasonable or without interest rate, Instant food, and pure water supply can facilitate their mechanism.
\end{abstract}

Keywords: Flood Risk Management, Coping Mechanisms, Food Vulnerability, Livelihood, Flooding Household.

\section{Introduction and Background}

Flooding is considered as a hazard that has the potentiality to damage or a physical event, phenomenon and or human activity that can lead to loss of life or injury, property damage, social and economic disruption, and environmental degradation (Twigg, 2004). Keller, Blodgett, and Clague (2008) have used the term hazard, disaster, and catastrophe to signify the interaction of humans with natural events such as earthquakes, volcanoes, floods, and wildfires Keller, Blodgett, and Clague (2008).

The location of Bangladesh is in the south-eastern part of the Hindu Kush - Himalayan $(\mathrm{HKH})$ region stretching between latitudes $20^{\circ} 34^{\prime} \mathrm{N}$ and $26^{\circ} 38^{\prime} \mathrm{N}$ and longitudes $88^{\circ}$ OI'E and $92^{\circ} 4 I^{\prime} \mathrm{E}$. The country has the Confluence of the Padma, Brahmaputra, and Meghna Rivers and their tributaries. The origin of the mighty rivers is mainly the Himalayas (except the river Meghna) and they discharge into the Bay of Bengal (Sheheli \& Khan, 2015). Bangladesh has experienced several floods such as 
1974, 1984, 1987, 1988, 1998, 2000 \& 2004 with a huge magnitude since I97I (FFWC, 2005). Every year about 26,000 square kilometers, which is approximately I8 percent of the country, gets flooded (Bangladesh Bureau of Statistics, 20I3).

Integrating the mass population, intensive agricultural production, dramatic variability of precipitation in the monsoon circulation, and the scale and dynamics of the river systems make a huge barrier to accomplish floodplain management in Bangladesh (Hofer \& Messerli. 2006). From the very beginning, people who have been constantly facing a flood, have traditionally developed various kinds of coping strategies to avoid or to decrease the loss due to floods in Bangladesh (Ahmed, Husain, Sattar, \& Chowdhury, 1998). Thus, it is important to understand how the victims of flood hazard cope or survive using their strategies.

This paper aims to identify the coping strategies of victims against floods along with assessing a respondent's extent of the practice of the strategies and to determine the flood coping ability of both household level and individual level. The study area is highly prone to flash flooding as they are situated beside the river Dud Kumari and Brahmaputra. Thus, the locality has developed a certain level of immediate coping strategies for themselves to manage the flood impacts and vulnerability. The coping mechanisms and strategic approaches by the victims are always significant as they can be correlated with other measurements such as instant action taking, flood loss minimization, flood forecasting, and warning services. However, this indigenous knowledge and strategies are often neglected. Understanding the direct involvement of the victims and their coping style with the incident will give a clear picture of flood management and measurement especially for the "instant action and postincident" part.

\section{Methodology}

\section{I Study Site, Study Design, and Data Collection}

Both qualitative and quantitative data collection procedures were used in the current study to collect data regarding the coping mechanism of flood-affected people between 9 and 23 June 2017. Two well-trained research assistants visited the Nageshwari sub-district of Rangpur district, Bangladesh which is one of the flood-prone areas of Bangladesh. We developed survey questionnaire and interview guidelines for focus group discussion (FGD) and key informant interviews (KII) to identify the coping mechanism and indigenous knowledge used by the flood-affected people to protect themselves as well as the barriers to use these mechanisms and knowledge. Respondents were selected based on their experiences and knowledge with the flooding and duration of their stay in the study area. We conducted audio-recorded interviews for FGDs and KIIs. We visited 500 households within the study area and identified IOO households of a total of I 40 respondents, based on convenience sampling. This sampling method was considered because of time constraints and minimal budget for the study. The selected households have been affected by the flood since they have started to live in the study area and were able to cope with the impacts of the flood by using various mechanisms during and after the flooding. We selected one to four respondents from every household to participate in this study to explore actions and measures towards adaptation and mitigation of vulnerability and damages during and after a flood in the study area.

A total of 100 households were selected for this study where 45 were from the area named Ratanpur which is the north most area of the Nageshwari Upazila. The area is situated near the river Dud Kumari which gets flooded especially during the moon soon period. Another 55 households were interviewed at the Nunkhawa which is situated just beside one of the biggest rivers (Brahmaputra) of Bangladesh. As the river is one of the oldest and gets flooded every year, the residents in this area have developed unique strategies to cope with the flooding. We selected IO participants for KII who were experienced in coping up with flood since their childhood in the study area, thus gathered indigenous knowledge and become experts to adapt the impacts of the flood. Besides, to understand how the capacity to cope up has failed in recent times, two FGDs were conducted with those who have been migrated from the flood-prone areas to the central town area.

\subsection{Data Analysis}

We reviewed the interviews and observations field notes for each day of data collection, which enabled us to capture key issues that emerged in different locations. If any new information came from interviews that were not included in the guideline, we incorporated a question in the guideline for further exploration. We transcribed audio-recorded interviews and group discussions. We developed a comprehensive coding system manually and then coded the data according to the research questions and objectives. Finally, we summarized the coded data according to the study objectives and themes. We performed the crossanalysis with the data which came from multiple tools to ensure the validity of the data. The survey questionnaire comprised both open and close-ended questions. For the questionnaire interviews, a comprehensive coding system was introduced to code the data according to the research objectives. The coded data were entered into a database system using SPSS software and finally was summarized in terms of the objectives. 


\subsection{Ethical Considerations}

We obtained informed verbal consent from all before interviews. We explained the importance of the study and the importance of their participation in the study. We also assured the anonymity and security of their information.

\section{Results and Discussion}

As the study area is a remote place, the literacy level is quite low. Almost 58 percent of respondents in the area are illiterate; rest had the combination of primary, secondary, and higher secondary. Religion has the usual ratio among the respondents. Muslims are the majority; more than 70 percent of respondents are Muslim followed by Hinduism. The average family type is a joint or large family with 7 to 12 members and 2-4 households in a family. Fortunately, living in a large household with several members has created a favorable environment for the flood victims. According to respondents, more family members can cooperate and work together to overcome the vulnerability after flooding. The study area is economically diverse with land cultivation; thus, 70 percent of the respondents live on farming and cultivation.

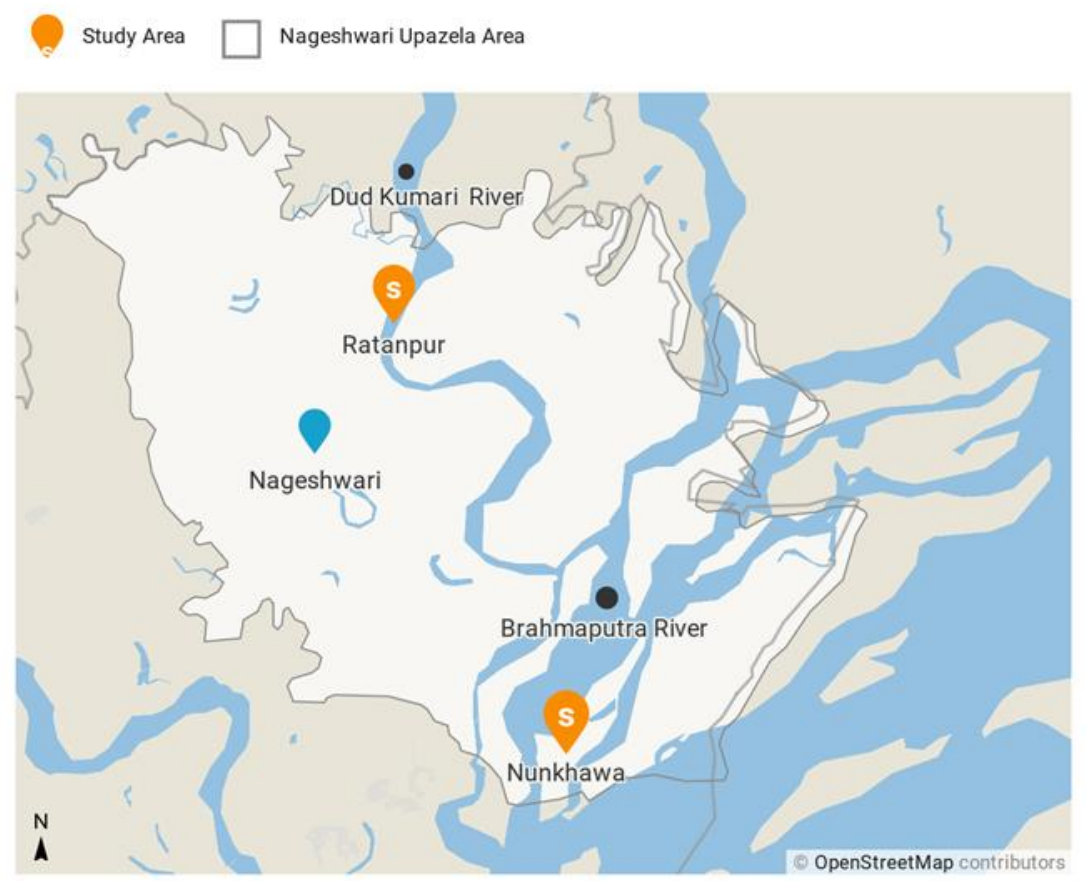

Figure I. Digitized flood zone with rivers entering into Negeshari Upazila

Businesses such as shop keeping, selling products in the city market, owning tea stall, boats, or auto (battery running vehicle) business and student as occupation are not uncommon. The unemployment rate is reasonable according to the respondent but it increases dramatically after flooding. Fifty-four percent of respondents have income level less than 5000 taka (\$60) and Forty-six percent of respondents have the income more than 5000 to 10000 taka (\$60-\$IO0) per month. According to the respondents, the income level is extremely low to defend the flooding circumstances for more than half of the participants.

\section{I Coping Mechanisms}

The study shows that financing and borrowing money is one of the major mechanisms used by the victims during and after the flooding. As it is an immediate solution with less or no interest source of money, 53 percent of the respondents borrow money from local neighbors and their relatives especially those who are living in the city or capital (Dhaka) during and post-flooding. Lending money from microcredit and NGOs or banks also common but only for those who have the possible capacity to repay and proper relationships with these organizations. The shelter center has been used by those (67\%) in 2016 especially by those who stay near to it. According to one key informant, "we prefer to stay at our home or relative's residents during the flooding season as shelter gets overcrowded and food and water are scarce". 


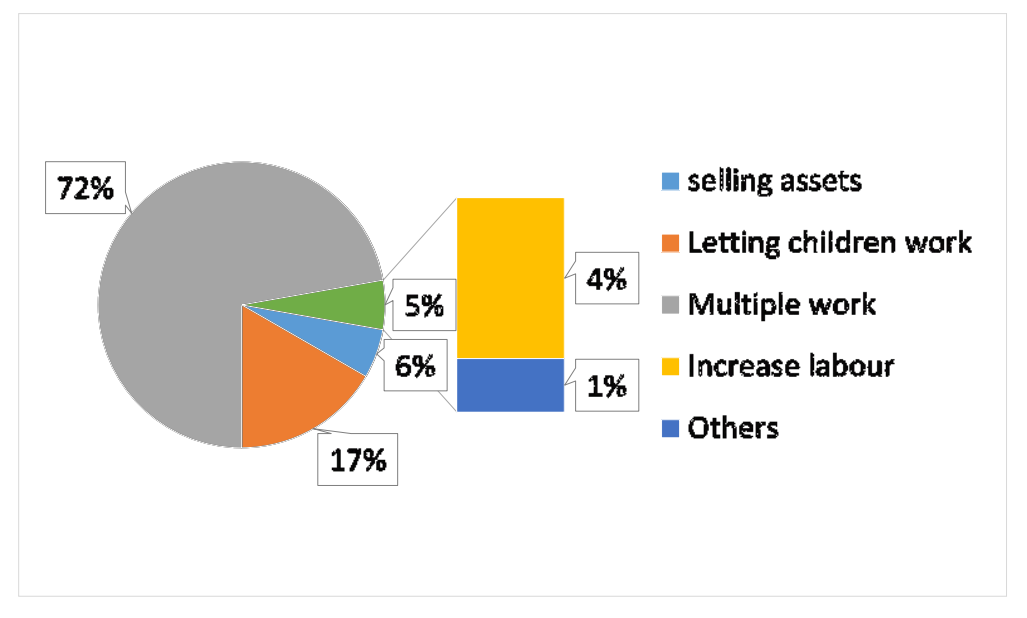

Figure 2. Initiatives taken by the victims to recover the vulnerable conditions

The instant actions or initiatives taken by the respondents are very diverse. Most of the victims recovered their condition by working for multiple times in croplands. For example, respondents stated that farmers must work at night or pull rented rickshaw after their usual labor on the field (Figure 2). For some household children who used to attend school, left school for some months to join work with their parents, or contribute labor for their households. Most of the poor victims had to sell their only or some portion of their assents (mostly lands) to recover their condition. Others had migrated themselves and start a new household to another safe place or even in the city Dhaka. Many of the respondents had developed a high raised traditional bed (Chouki) to keep them safe from floods.

During and after the flood, cooperation is a significant part of the coping mechanism. Most of the cooperation was boiled up with relatives as they are more likely to help without return (e.g. helping with money without asking to return). Some relatives help by providing shelters. For most of the respondents, it is also important to get connected with several NGOs and GOs to get light scheme credit or even food and water support. Through the collective relation, victims (52\%) expect to have financial support from relatives, neighbors, and different institutions especially without any return and with less or interest-free. Both victims and non-victims involve themselves in rebuilding houses, re-stocking livestock, securing an income, repaying borrowed money, treating affected family members, and restoring other aspects of life such as children's education.

Respondents (89\%) take valuable stuff and cattle to the safe place immediately after the flood hits. For the victims, praying to god psychologically affects a lot while facing unpredictable circumstances as most of the respondents have the spiritual beliefs that God would save them from this situation. During the flooding, 15 percent of victims look forward to having the material support (e.g. food, water, sleeping elements, bamboos, woods, fuel, etc.) along with the financial support from the relatives and/or the neighbors.

\subsection{Obstacles of the Existing Mechanism}

It is common for everyone to use mechanisms to minimize the loss and recover from flooding, but most of the respondents revealed that these mechanisms also have some barriers which prevent them to recover fast and effectively. The most common problem they have is financial repayment. For $78 \%$ of the respondent, it is hard to pay back the borrowed money within the given time by relatives or any institutions. Moreover, a high rate of interest holds back the possibility to even pay the actual amount for highly vulnerable people. Respondents have stated that they rarely get any financial help even from relatives without any conditions of time and/or interest. Organizations and institutions such as NGOs also have an interest limit and $89 \%$ of respondents think that the rate is very high for them. Another significant problem that victims face is to keep the mortgage for borrowed money. They have to keep their important asset as mortgage to lend money from local wealthy neighbors, for which at some point some of the victims (especially the poor) lose their assets for being failed to repay. A respondent said, "I borrowed money from my relative but I had to keep my land documents as the mortgage and still I couldn't pay back the money which I have borrowed”. More than 80 percent of respondents mentioned that they hardly got financial aid without any conditions.

According to the study, for 52 percent of the respondent, it took two to three months to recover. Even for some respondents (I4\%), it took more than four nearly five months to recover. Some poor victims are still fighting to change their vulnerable situation by the recent flood incident. 
Among the respondents, the ratio of owner and non-owner of cultivable land was 56\%, and 44\% and more than $90 \%$ of the non-owner stated that they faced difficulties to repay their debt or rent to the landowners.

All most all of the months in Nageshwari are the suitable season for the cultivation of different crops, thus, there is no season when floods do not wash away the crops field and sunk to the ground. Furthermore, flooding also creates several types of soil problems and washes away all the fertilizers that have been used already and that has forced to increase the cost of fertilization. More than 50 percent of the uncertainty comes from the "crop-damaging" during and after the flood. More than half of the respondents have faced crop waste cattle loss simultaneously. Because of the extreme financial crisis, it took up to $5-$ 6 months to recover after the flood for $34 \%$ of the respondents.

\section{Conclusion}

The respondents of the study area have been minimizing the damage of flood and cope up with the vulnerability made by the flooding. The indigenous knowledge of the flood victims has shown the effectiveness from the very beginning and now it has become an important flood management element. Thus, this study focused on the strategies and coping mechanisms of the victims against flood, by investigating the real exercise and experiences of the victims in the study area.

The poor households were the most vulnerable during and after the flooding as it damaged their crops, livestock, fish stocks, property, and lives. Women works harder than men to ensure more effort to look after all family members and animals to ensure their safety. Even though lending money from relatives or neighbors is the most common strategy to become financially stable, for most of the victims borrowed money from relatives is not enough to recover the aftermath of the flood. As a result, most of the respondent has to depend on credit loan from different organizations. Poor households became even more vulnerable and some of them are still unable to recover the circumstances.

NGOs and GOs or any private organization should bring different kinds of training, credit, technological supports to facilitate the coping mechanisms of the victims. As the number of shelter center is low, schools and health stations should be introduced and build up with emergency shelter center in every place. Children who are displaced by the flood should be supported by the $\mathrm{NGO}$ or GO organizations to continue their education and in this case, governmental and non-governmental partnerships to support reducing poverty and vulnerability can increase the stability of the victims and help them recover within a short time.

According to the UK Environment Agency, the threat from flooding is continuous and will not leave us. On the other hand, it cannot be eradicated but the effect can be reduced (Kundzewicz, I999). It is natural phenomena but minimizing the consequence is on the hand of mankind. Thus, along with adequate help and support, global recognition of existing cope-up mechanisms of the victims would be a strong influencing factor for achieving a sustainable flood management system.

\section{References}

Ahmed, S. M., Husain, A. M., Sattar, M. G., \& Chowdhury, A. M. R. (I998). A quick assessment of flood losses and post flood rehabilitation needs in BRAC's programme areas. Experiences of deluge: flood, I-29.

Bangladesh Bureau of Statistics. (2013). Publications of Bangladesh Bureau of Statistics (BBS), Statistics and Informatics Division, Ministry of Planning. Retrieved from http://bbs.portal.gov.bd/sites/default/files/files/bbs.portal.gov.bd/page/b7347IIb_5a89_4d8b_97de_949debfc e292/BBS_Publication.pdf

Hofer, T., \& Messerli, B. (2006). Floods in Bangladesh: history, dynamics and rethinking the role of the Himalayas. Ecology, 29, 254-283.

Keller, E. A., Blodgett, R. H., \& Clague, J. J. (2008). Hazards: Earth’s Processes. Disasters, and Catastrophes: Pearson Prentice Hall, Toronto, ON.

Kundzewicz, Z. W. (1999). Flood protection—sustainability issues. Hydrological Sciences Journal, 44(4), 559-57 I.

Sheheli, S., \& Khan, M. A. M. (2015). Coping strategies of women in flood prone areas of Bangladesh. Progressive Agriculture, 26(2), I55-I67. https://doi.org/I0.3329/pa.v26i2.25977

Twigg, J. (2004). Good practice review: Disaster risk reduction. London ODI. 9. I3I- I39.

\section{Copyrights}

Copyright for this article is retained by the author(s), with first publication rights granted to the journal. This is an open-access article distributed under the terms and conditions of the Creative Commons Attribution license (http://creativecommons.org/licenses/by/4.0/). 